\title{
Reconceptualizing Job Control in Participatory Interventions - Collective Sensemaking as a Missing Link'
}

\section{Esben Langager Olsen²}

PhD Student, Copenhagen Business School, Department of Organization, Denmark

\section{Christian Dyrlund Wåhlin-Jacobsen}

Assistant Professor, Copenhagen Business School, Department of Organization, Denmark

\section{Johan Simonsen Abildgaard}

Senior Researcher, The National Research Centre for the Working Environment, Denmark

\begin{abstract}
Participatory organizational-level interventions where employees are invited to voice suggestions for improving the work environment have been claimed to increase job control. However, empirical studies suggest that the relationship is conditional, and the underlying mechanisms are not well understood. To further our understanding, we highlight various weaknesses in current individuallevel conceptualizations of job control and argue that employees' collective sensemaking relating to their job control is an important, yet overlooked factor. To demonstrate the principles of this sensemaking and how it shapes the participants' engagement in the intervention, we analyze interactional data from an intervention with blue-collar employees. Based on this analysis, we discuss the implications of adopting a sensemaking perspective for research and practice.
\end{abstract}

\section{KEYWORDS}

Interventions / Job control / Organizational development / Participation / Qualitative methods / Sensemaking / Workplace improvements

\section{Introduction}

articipatory organizational-level interventions (POLIs) enable employees to address problems related to the work environment by providing an arena for discussing working conditions and suggesting improvement initiatives to management. In recent years, POLIs have received increased attention in the work environment literature, and their use is recommended by international bodies such as the World Health Organization and the European Network for Workplace Health Promotion (Burton 2010; European Network for Workplace Health Promotion 2007). Besides improving the well-being of employees and preventing work-related health issues (Egan et al. 2007; Mikkelsen et al. 2000; Nielsen et al. 2010), POLIs are also claimed to lead to increased

\footnotetext{
${ }^{1}$ You can find this text and its DOI at https://tidsskrift.dk/njwls/index.

${ }^{2}$ Corresponding author: Esben Langager Olsen, PhD Student, Copenhagen Business School, Department of Organization, Denmark. E-mail: eno.ioa@cbs.dk.
} 
sense of fairness, justice, social support, and, as is the focus of this paper, increased job control (Egan et al. 2007; Nielsen 2013; Nielsen et al. 2010).

It has been argued that the participatory element of POLIs specifically leads to increased job control (Egan et al. 2007; Mikkelsen et al. 2000; Nielsen et al. 2010). Job-control is often described as a mechanism that can improve employee health and well-being (Bambra et al. 2007; Bond \& Bunce 2001; Hätinen et al. 2007). For example, high job control has been associated with high levels of job satisfaction and reduced discomfort (Parker \& Price 1994), and Karasek and Theorell (1990) argue that job control can protect the employee against the strain caused by excessive work demands. POLIs can thus be seen as a method to increase job control and in turn improve employee health and well-being.

However, there are several uncertainties regarding the purported effect of POLIs on job control. For one, empirical studies investigating whether POLIs increase job control show mixed results (e.g., Egan et al. 2007), with many studies reporting little or no change, suggesting that the link is not automatic. Second, a recurrent problem for POLI studies is that the focal interventions often lead to job redesign, which in itself is likely to increase job control (Daniels 2006). Therefore, it is difficult to determine whether changes in job control is an effect of participating in the POLI, or the job redesign derived from it. Third, at a more general level, the potentials and limitations of the different forms of participation offered in POLIs have been the topic of critical debate, with scholars advocating clearer specification of the particular participation schemes, as the degree of control offered to participants is found to differ greatly (Abildgaard et al. 2018). In relation to this, it has been argued that POLIs rarely increase employee's decision authority significantly (Busck et al. 2010). On the contrary, POLIs may act as a discrete method for transferring the responsibility for the work environment from management to the employees, eventually causing a deterioration in the psychosocial work environment. Taken together, there are plenty of contingencies affecting the link between POLIs and job control. Unfortunately, these contingencies are rarely studied in detail, which limits our understanding of how POLIs actually work. Since most POLI activity revolves around discussions between employees and managers at the group level, we consider it appropriate to expand the research on POLIs and on job control by looking into how these processes unfold. We propose collective sensemaking (Maitlis 2005) as a productive lens for studying POLI processes since it foregrounds the processes through which organizational actors negotiate future action on a moment-by-moment basis, based on past events.

The aim of this paper is, through detailed qualitative case examples, to explore how POLI participants make sense of their job control, the types of job control they have and make available. We show how the discussions both reflect the participants' sense of job control and how this sense can be confirmed or altered through the POLI process. We finally discuss our findings in relation to POLI and job-control research and practice.

\section{Participatory organizational-level interventions and job control - a critical review}

In the fields of work environment and work psychology, job control is often defined and operationalized as the social authority over decision-making in relation to work tasks (Häusser et al. 2010; Karasek \& Theorell 1990; Van der Doef \& Maes 1999). The work 
of Karasek and Theorell (1990) has been especially central to discussions of job control in relation to occupational health and well-being, and although other approaches such as the job demands-resources model (Bakker \& Demerouti 2007) have since gained prominence, the conceptualization of job control suggested by Karasek and Theorell is still used today (e.g., Aronsson et al. 2019; Fritz \& Knippenberg 2019; Gonzalez-Mulé \& Cockburn 2017)

With inspiration from the work of Karasek and Theorell, job control is typically approached in the POLI literature at the individual level as something employees perceive (e.g., Bourbonnais 2006; Hätinen et al. 2007; Landsbergis \& Vivona-Vaughan 1995; Mikkelsen et al. 2000). When employees' perceived job control changes during the intervention process (as measured by questionnaire data, for example), the change is typically attributed to the intervention, suggesting that the perception is otherwise thought to be stable.

However, there are important caveats regarding the purported POLI-job control link. Empirical studies demonstrate that POLIs do not always lead to increased job control in practice. While a number of intervention studies support the claim that participatory interventions increase various measures of job control (e.g., Bond \& Bunce 2001; Maes et al. 1998; Wall \& Clegg 1981), an equally large number of studies show only very small or no increases in measures related to job control (e.g., Bourbonnais 2006; Bourbonnais et al. 2011; Landsbergis \& Vivona-Vaughan 1995; Mikkelsen et al. 2000). The mixed results suggest that the relationship is contingent on factors not yet identified.

Furthermore, the effect of the participation component in POLIs is obscured by the fact that POLIs can lead to changes in how work is organized, which may increase job control in itself. For example, in a study by Maes and colleagues (1998), a task group of employees was established through a POLI and given authority over the entire production process. And in Wall and Clegg's classic study of work redesign (1981), a 'fundamental shift of responsibilities from the supervisory roles to the established teams' was undertaken in the intervention under study (p. 41). Also, Bond and Bunce (2001) specifically prescribed that the participatory groups in their study should 'develop and implement work organization changes that might increase people's job control' (p. 294), such as new ways of distributing assignments. In these cases, it is not possible to say whether increases in job control were caused by the employees' engagement in POLI activities, or the particular changes these activities lead to. Unfortunately, many POLI studies do not give a detailed account of the specific changes resulting from the POLI, which makes attribution of increases in job control to the participation component of the POLI difficult (see, e.g., Hätinen et al. 2007).

In addition to the shortcomings relating to the effects of POLIs and their interpretation, there is a lack of conceptual clarity regarding the nature of job control. The process of how individual employees assess such aspects and their relative significance for the employees' overall level of job control has not been explicated. Thus, little is known about how employees come to form their job control perceptions. One consequence of this lack of knowledge is that it is unclear whether differences in perceived levels of job control among employees holding similar jobs, for example, mainly reflect differential access to informal means of control, or merely assess their (otherwise similar) situations differently.

It is also known that employees typically hold different degrees of job control in relation to different job aspects (Breaugh 1985), and that only increases in job control that allow employees to mitigate the specific demands they experience are likely to buffer against strain (Häusser et al. 2010). General job control may thereby hold 
less importance for employees than job control in key areas, and it would thus seem especially relevant for POLIs to increase job control in these areas. Here, Karasek and Theorell (1990) discern between decision authority and skill discretion, but others such as Gangster (1988) has argued that seven domains of job control exist (tasks, pacing, scheduling, physical environment, decision making, other people, and mobility). In addition, it has recently been suggested that the increasing complexity in organizations affords new ways of assessing job control (Väänänen \& Toivanen 2018). While employees today in general have more autonomy than previously, the autonomy is increasingly tied to, or contingent upon, a complex of inter- and intra-organizational factors. Increased autonomy is no longer positive by default, but should be considered in relation to the employee's ability to complete the task within the organizational ties. Thus, attending only to employees' general job control may give a rather limited understanding of whether and how POLIs can influence job control in practice.

At a more general level, viewing job control as something that is perceived at the individual level does not reflect how POLIs are fundamentally social activities involving employees and managers in shared decision-making. For one, different POLI groups will most likely have different degrees of success in improving their work environment and should accordingly experience different levels of change in their job control. Yet, only few intervention studies discuss the causes of differences between subgroup in how the participants' job control is affected by the intervention (e.g., Tsutsumi et al. 2009). Second, the trajectory of group discussions is not simply a product of the attitudes or perceptions held by the individual participants; rather, it evolves, in discussion, on a turn-by-turn basis, with even single comments occasionally having a profound effect on the outcomes of the discussion (Boden 1994; Pennanen \& Mikkola 2016). Thus, to understand how participatory processes lead to changes for the participants and the workplace, it is necessary to attend to the participants' interactions.

POLI participants do not only assess their job control when faced with questionnaires. Rather, studies suggest that employees more routinely (and informally) assess their job control in relation to influencing their working conditions. These ongoing assessments can then influence participants' attitude towards POLIs. For example, if the work environment has proved consistently unamenable, this may produce preconceived skepticism and decrease engagement (Harlos 2001; Pohler \& Luchak 2014). Thus, employees with low perceived job control may pose a practical challenge to the intervention process (Dahl-Jørgensen \& Saksvik 2005), for example by staying silent or voicing counterproductive critique.

While it remains theoretically likely that employees may experience increased job control by participating in organizational decision-making processes, more knowledge is needed about the mechanisms that determine under what circumstances this is the case (Nielsen \& Miraglia 2017). In order to further develop our understanding of the relevant social mechanisms in particular, we present a complimentary theoretical perspective for analyzing the POLI-job control link based on collective sensemaking theory.

\section{Job control as enacted through processes of collective sensemaking}

In advancing the theorization of organizational interventions, recent studies have drawn upon sensemaking theory to focus on the processes of meaning-making during 
workshops and other intervention activities (Abildgaard \& Nielsen 2018; Ala-Laurinaho et al. 2017). Sensemaking theory provides a conceptual framework for describing how collectives construct shared understandings of their experiences on an on-going basis and decide how to proceed (Garfinkel 1967; Maitlis 2005; Weick 1977). Weick, arguably the most influential scholar in the sensemaking literature, coins sensemaking as simply the 'making of sense' (Weick 1995, p. 4) emphasizing that sensemaking is a processual phenomenon constantly being re-enacted. From a sensemaking perspective, figuring out what characterizes the current situation (i.e., 'what is going on here') does not happen automatically (Garfinkel 1967: 79) and different understandings of the current situation imply certain actions as appropriate. This means that discussions of 'what is going on here' also holds implications for 'what should we do next'.

What is characteristic of collective sensemaking processes relative to individual sensemaking is that meaning is coordinated among the participants, allowing them to subsequently act as a collective (Boyce 1995). This coordination of meaning does not imply that all participants agree (Taylor \& Robichaud 2004). Rather, the point is that meaning becomes socially enacted, and is thereby acted upon as if true and agreed upon. Collective sensemaking processes can be observed in how organization members negotiate accounts about the organization in their interactions (Maitlis 2005). Accounts are 'discursive constructions of reality' (Maitlis 2005: 21), which render a situation meaningful and thereby actionable for the recipients. Accounts are structured around pieces of information, or cues, extracted from the organizational environment, which are then imbued with meaning. The cues could stem from a number of sources, such as narratives of past management decisions, numbers on a spreadsheet, or operational occurrences (e.g., unexpected breakdowns of production machinery). Based on the cues they extract and the meaning they imbue them with, organization members may offer different accounts of the same situation. This feature allows accounts to be employed strategically, for example, by suggesting that one course of action is more desirable than another.

However, there are also contingencies, which must be met for accounts to influence collective sensemaking: accounts must be produced so as to be understandable and convincing to the listeners in the setting, which involves utilizing information that is familiar, or at least taken as credible by the listeners (Garfinkel 1967). Also, others might choose to challenge the account, for example, by offering competing accounts or modifying the account through their own formulations, whereby the accounts can become enrolled in agendas that their original authors did not intend (Maitlis 2005).

To summarize, collective sensemaking provides a relevant framework for understanding the link between POLI and job control for three reasons: first, a collective sensemaking perspective highlights and helps explicate the social processes whereby groups arrive at and enact decisions, which, as mentioned previously, have been overlooked in previous POLI studies. Second, the sensemaking perspective is also particularly well suited for identifying shifts in understanding, including shifts in which understanding of job control is drawn upon by the participants in their discussions (e.g., general, domainspecific, or tied job control). Third, sensemaking is especially prominent when participants need to orient themselves towards a changing or ambiguous situation (Maitlis 2005). Engaging in a POLI is likely to constitute such a situation because of how the participatory decision-making processes differ from the chain of command that is typically followed. Also, POLIs contain an inherent unpredictability for the participants as 
the fate of the employees' suggestions often rests with nonpresent organization members, such as the upper management, which have the requisite authority to approve or disapprove the suggestions. Since the participants can only assume how others will react to their suggestions, their decisions about which ideas to pursue are likely to reflect their ongoing assessments about the extent of their control.

Thus, we suggest that collective sensemaking provides a supplementary approach for studying the changing enactments of job control in POLIs. This implies a fundamental shift in the way job control is analyzed. Rather than approaching job control in POLIs as an individually perceived and thus decontextualized phenomenon, we instead consider job control in POLIs to be negotiated and situated in the context in which it emerges (Maitlis 2005). We pose the following research question:

How can we understand job control in POLIs using a sensemaking lens, and what implication does a sensemaking-based understanding of job control have for research and practice of POLIs?

\section{Method}

The data in this article was drawn from a POLI for industrial operators in a Danish pharmaceutical company. Generally, industrial operators ${ }^{1}$ are considered to have a low degree of control over the job demands imposed on them (Karasek \& Theorel 1990; The National Research Centre for the Working Environment, 2018). The aim of the present POLI was to improve the work environment of industrial operators by implementing a system for continuous participatory improvement. The system was hypothesized to help the operators identify strenuous work tasks and develop realistic solutions for decreasing job demands or increasing job resources in relation to these (for a detailed description of the intervention program, see Gupta et al. 2015; and the intervention manual in Danish, Wåhlin-Jacobsen et al. 2017).

Among other elements, the intervention featured a series of action-planning workshops (APWs) in which groups of 6-10 operators discussed solutions to problematic working conditions that they had identified at a previous workshop. Since the participating operators were members of the same work team or shift, they could engage in the discussions based on their shared tasks and experiences. The participants were mostly unskilled, but with a high degree of experience for the job. The operators' line managers also participated and were instructed to provide information when needed and participate in the discussions that fell within their managerial discretion. The workshops were facilitated by an external consultant or a member of the research group following written instructions.

A total of 11 APWs were conducted with different employees appearing in each. All APWs were audio recorded, yielding more than 28 hours of interactions, which was subsequently transcribed. The transcript material was supplemented with additional data on nonverbal aspects of the group discussions gathered from the field notes of workshop observers.

In order to investigate the link between the POLI and job control, we began the analysis by reading the data corpus repeatedly to familiarize ourselves with the content. We applied a concept coding strategy (Saldaña 2015), paying attention, in particular, to 
concepts related to POLI participation and job control. During this stage of the analysis, we noticed that there was substantial difference between workshops. In some, the collaboration went smoothly. In others, the employees resisted the workshop agenda, and they only agreed upon few action plans.

To form a distinct corpus for the analysis, we identified when the theme of each action plan was first brought up, and tracked later occasions at the workshop where the particular action plan theme was mentioned. To investigate the emerging theme of social dynamics of POLI action planning and job control, and due to the negotiated and collective interactions of job control and action planning that emerged, we employed a subsequent theory based, focused coding strategy (Saldaña 2015) based on sensemaking theory. In the focused coding, we repeatedly read the transcript sequences for the action plans paying attention to how the participants' control-related sensemaking and accounts came to inform the action planning within each workshop.

We present the results of the analysis in the form of a case study focusing on three sequences from three different APWs. We selected these sequences because they illustrate different aspects of how job control was negotiated in POLI activities. The sequences are typical examples of the participants' sensemaking processes and how shifts in dominant accounts occurred throughout the workshop meetings; still, they also reflect the particular context of our study. Thus, we do not expect the specific details of the three cases to be generalizable to other settings, but rather the main mechanisms regarding how job control (in its various forms) is made sense of and enacted. We present the sequences in a narrative style, providing background information, condensed descriptions of relevant events in the workshop (Van Maanen 2011) and transcribed excerpts from the workshop recordings in our presentation of the analysis.

In the analysis, we have changed all names and translated all quotes into English. We have aimed to preserve the structure of the participants' utterances in order to show the improvised nature of the interaction. To preserve relevant details of the participants' utterances, the transcripts employ various specialized symbols presented in Table 1.

Table I Transcription guide

\begin{tabular}{ll}
\hline Symbol & Meaning \\
\hline $\mathbf{( . )}$ & Audible pause \\
\hline $\mathbf{( ( ) )}$ & No break or gap between utterances \\
\hline $\mathbf{\ldots}$ & Transcriber's comments or anonymized \\
\hline $\mathbf{-}$ & Transcription starts or ends in the middle of utterance \\
\hline WORD & Indicates that the word is cut off \\
\hline
\end{tabular}

\section{The workshops}

At the beginning of each workshop, the facilitator informed the participants about the workshop agenda, and the aim of developing action plans to address problematic working conditions. The facilitator presented the group with a chart outlining the issues they had brought up in an earlier 'screening' workshop and encouraged the participants to 
suggest improvements. The facilitator would then interview the participants about the identified issues in order to bring forth a detailed understanding of what the participants believed to be relevant causes and how the problem could be mitigated.

The participants often took different positions on the issues, leading to discussions moderated by the facilitator. When the participants came to an agreement, the facilitator instructed them to fill out an action plan template describing who would do what, and by when. The facilitator told the operators that they were to implement the action plans after the workshop with the assistance of their line managers or other relevant organization members. In order to be feasible, actions plans had to fall somewhat within the operators' influence, referred to by the facilitator as their 'action radius'. The facilitator encouraged the participants to monitor the progress of action plans after the workshop using the company's established system.

Table 2 Intervention APWs discussed in the analysis

\begin{tabular}{|c|c|c|c|}
\hline Sequence number & $\mathbf{I}$ & 2 & 3 \\
\hline $\begin{array}{l}\text { Operator participants } \\
\text { (participants cited) }\end{array}$ & $\begin{array}{l}8 \text { (Ronny, Frank, } \\
\text { Cooper, Jill) }\end{array}$ & $\begin{array}{l}9 \text { (Jesse, Jack, Jimmy, } \\
\text { Huey) }\end{array}$ & 4 (Bob, Tony, Roy) \\
\hline Line manager & $\begin{array}{l}\text { Paul (Laura also } \\
\text { present) }\end{array}$ & Laura & Laura \\
\hline Observers & $\begin{array}{l}\text { Two research } \\
\text { assistants }\end{array}$ & $\begin{array}{l}\text { Research assistant, } \\
\text { middle manager }\end{array}$ & Research assistant \\
\hline $\begin{array}{l}\text { Number of agreed- } \\
\text { upon action plans }\end{array}$ & 2 & 5 & 6 \\
\hline $\begin{array}{l}\text { Focal understanding } \\
\text { of job control }\end{array}$ & General job control & $\begin{array}{l}\text { Task-specific and tied } \\
\text { job control }\end{array}$ & Tied job control \\
\hline
\end{tabular}

\section{Analysis}

\section{Sequence I - A persistent account of lacking general job control}

The first excerpt shows how the operators' sensemaking regarding the feasibility of changing their work environment led to the construction of an account of them having too low general job control for the intervention to be relevant. In accordance with the intervention manual, the facilitator introduced the concept of action radius, and attempted to use it to as a way to mitigate an emerging pessimism. However, this did not go as planned, and critical remarks ensued when the facilitator asked how the participants felt about developing action plans. In the following excerpt, we see how two accounts of the operators' job control emerged through the collective sensemaking process, with the facilitator constructing one and the operators with the line manager constructing the other:

\footnotetext{
Ronny: $\quad=\ldots$ but there are some of those things ((i.e. identified work environment problems)) that we are not in charge of at all (.) and no matter what we think and do, we can't change them

Facilitator: That's a good point, that there is something that's beyond your=
} 


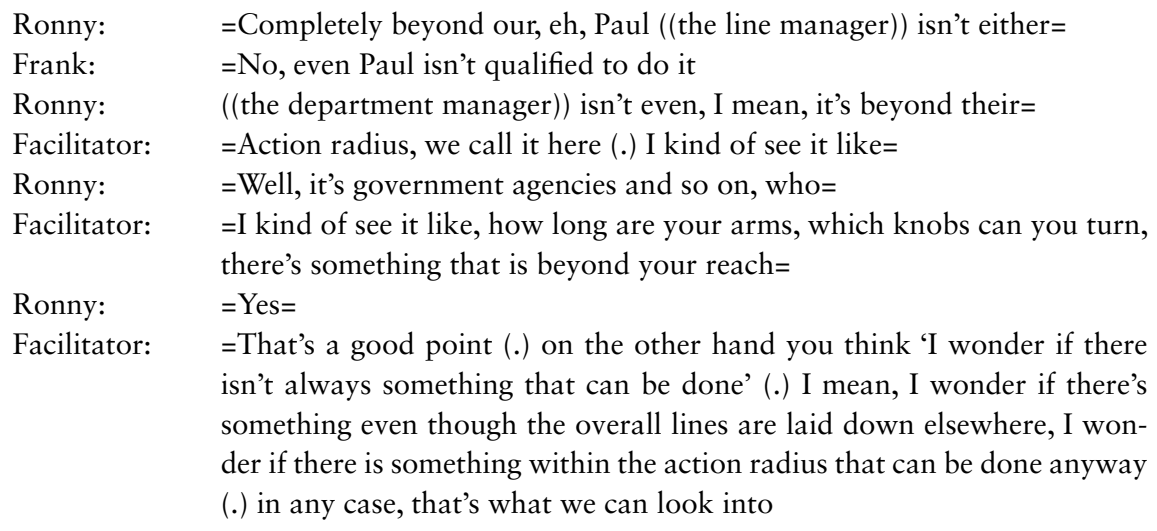

In the excerpt, we see how the operators express that some of the issues raised in the screening workshop are outside of their control and even outside their line and department managers' control. Ronny describes these matters as controlled by 'government agencies', thereby providing a warrant for the operators' skeptical stance. From our supplementary data, we know that the production process was subjected to both national and international regulation, effectively determining how to perform most work tasks and which equipment could be used, for example. The other participants of course knew this as well.

Next, the facilitator picks up on Ronny's statement that some problems are outside of their control, using it as an opportunity to introduce the action radius. While acknowledging the employees' objections, the facilitator also poses what seems like a rhetorical question ('I wonder if there isn't always something that can be done'), suggesting that the operators hold at least some influence, though they may be in not be full control. By inviting the operators to explore the opportunities within their action radius, the facilitator implicitly suggests that the operators might not be aware of, or have not critically assessed, their options, suggesting their general job control to be more significant than they believe.

The excerpt thus illustrates how different ways of constructing the operators' job control can compete in collective sensemaking processes. The facilitator constructs jobcontrol as something opaque and potentially wider than it appears at first glance, while the operators hold the image of their job control as both apparent and limited.

As it will become clear, the operators did not commit to the facilitator's account, and after further protests from the operators, the facilitator remarked that the operators seemed to be thinking 'what's the point?' The next excerpt features various employees' responses:

\begin{tabular}{|c|c|}
\hline Cooper: & 's not about that, 'what's the point,' because I= \\
\hline Jill: & $=$ No, we know that already= \\
\hline Cooper: & $\begin{array}{l}\text { =Because I, well I could very well go take on something with ((an operator } \\
\text { not present )), let's say the buckets; I was in the first workshop regarding } \\
\text { what was made in ((an in-house ergonomics project)); what you first run } \\
\text { into is that if you change the bucket size, then it won't fit the ((emptying } \\
\text { tables)) anymore }\end{array}$ \\
\hline Facilitator: & $\mathrm{Mm}$ \\
\hline
\end{tabular}


Cooper: The next thing is that there isn't space in the ((production management system)) to take in that many buckets, and we don't have the freezing capacity for them. This means if you take the buckets, then when you start working on it, you run into all these challenges, so what you originally thought, 'oh the buckets, that'll be easy,' no, it must also be certified suppliers and the like, so suddenly=

Facilitator: =Yes=

Cooper: =From one thinking, 'well, that's a 15 -minute job,' it is the kind of thing that no one can manage anymore

In this excerpt, Cooper (backed by his colleague Jill) first addresses the facilitator's comment regarding the employees' stances towards the intervention, producing instead an account of a range of problems experienced in a previous project that tried to address one of the identified issues. Specifically, Cooper mentions a range of technical problems, such as how changing the equipment would require additional validation procedures or alterations of the production space, all of which would imply costly production downtime. Both operators and line managers described such complications repeatedly during the workshops. In the account, Cooper had been powerless in the face of an issue that had at first seemed actionable, thereby countering the facilitator's account that there were 'knobs to turn'. The account supports the operators' construction of their general job control as lacking.

Throughout the rest of the workshop, the negotiation persisted between the facilitator's argument of possible initiatives within the operators' action radius and the operators' ability to affect the identified issues. The operators repeatedly voiced dissatisfaction over having identified issues they felt were outside their control. Towards the end of the workshop, one of the employees' line managers (Paul) urged the operators to go after 'low-hanging fruits', referring to action plans that could be implemented through the means available to the operators. One example was inviting the department manager to visit the production site to talk through the various problems the operators were facing. As a result, the operators eventually agreed upon two action plans; however, these action plans did not address the issues the operators had described as the most critical. The workshop ended with the operators expressing their dissatisfaction with the intervention design, arguing that they would have identified more actionable problems, had they understood the premise earlier. Thus, focusing on issues considered by the operators to be beyond their influence accentuated the operators' account of having low general job control. In this way, the 'action radius' came to symbolize the narrow limits of the operators' control rather than the 'knobs within reach' that the facilitator initially suggested the operators to look for. However, both the facilitator and the employees' focus on their general job control also meant that relatively little time was spent discussing more specific strategies to influence their situation.

\section{Sequence 2 - Influencing job control enactment by identifying new change strategies}

In contrast to Sequence 1, this next sequence exemplifies how the participatory element may lead to employees acting as if having an increased chance of influencing their work environment and thus having an expanded level of job control. In the APW in 
this sequence, the participating operators discussed their problems getting in touch with maintenance staff when machines malfunctioned during night shifts. The operators rarely knew what to do, leading them to call staff from other departments in search of help, or improvising their own repairs. The operators seemed jaded about their chances of alleviating this problem since previous complaints to the management had not resolved the matter. For example, one operator stated:

'I can note ((the problem)) (.) and I have called attention to ((it)) (.) because attention has been called to this many times (.) you can say that my action radius is no wider'.

Another operator stated that the management would neglect the issue if they could not see any immediate financial gain, a recurrent account presented by operators in relation to persisting work environment problems. In contrast to the operators' accounts, line manager Laura described the intervention as providing a new situation:

'Please, could I persuade you to, all those (.) limitations you're now imposing because you've earlier been told "no" or something, that those, those we can just put aside, and then we start anew, then we go back, if you find it important that we have maintenance on a night roster, then that's the kind of idea we'll go with'.

The negotiation between variants of these two accounts continued, with various operators protesting and arguing that it could not reasonably be the responsibility of the operators to resolve the issue. One operator suggested simply shutting off malfunctioning machines for the remainder of the shift, bringing the production to a halt and thereby calling the attention of senior management. In response, Laura repeatedly urged the operators to give it another try. Over the course of the discussion, the operators' labelled the situation as 'frustrating' and 'a damn shame', since the team's work was labeled a 'bottleneck' step in the production. Downtime in this area would create problems further down the line. The operators characterized senior management as very concerned with keeping costs down; however, risking increased downtime by refusing to implement a night rostering system for maintenance was seen as irrational.

Next, the facilitator used the cues provided by the operators to argue that the operators had a strong point, since the problem affected both the well-being of the operators (due to the stress of dealing with malfunctioning machines) and production efficiency. Laura sided with the facilitator, adding that the production terms for the department were changing:

Laura: $\quad$... Back then, when we got a 'no', perhaps we had gaps in our eh plan, meaning it maybe didn't matter that much if we had malfunctioning machinery, we could easily reach our performance goals

Jesse: $\quad$ Are you thinking=

Laura: We are under pressure, eh, we are under pressure already this year

Jesse: $\quad \mathrm{Mm}=$

Laura: We will surely be under pressure next year, and the year after that I don't even think that we will have all the optimizations in place in our department to reach ((the production goal)), and then every (.) gap will come to matter for us 
The operators then proposed that maintenance technicians should be available to the operators all hours of the day. Identifying only affirmative arguments, the operators started to discuss how to formulate the suggestion in the form of an action plan. Laura proposed that the group could strengthen their argument by making their own economic assessment of the costs and potential gains associated with the proposal before presenting it at the department meeting, stating 'the better prepared we are, the easier it is to get our way so to speak'. After some discussion, the group pursued Laura's overall plan:

$\begin{array}{ll}\text { Facilitator: } & \text {... so one task on this action plan could be 'talk to James' ((head of } \\ \text { department)) } & \text { 'Get data' and, and } \\ \text { Laura: } & \text { Yes I was just about to say, for example in } 15 \text { minutes, how many calls for } \\ \text { Huey: } & \text { maintenance have there been, how many hours is this about } \\ \text { Facilitator: } & \text { Yes } \\ \text { Huey: } & \text { It's obvious that we know the answer already, if you get up there and say } \\ & \text { 'well it's one and a half hours ( (of downtime)), we think it would be really } \\ & \text { good to invest } 30,000 \text { euro in that', then you would probably get a no } \\ \text { Jimmy: } & \text { One and a half hours, that's more than } 30,000 \text { euro } \\ \text { Laura: } & \text { Yes, you could recalculate it into produced ((goods)) } \\ \text { Jimmy: } & \text { Yes, yes, it doesn't take a whole lot } \\ \text { Huey: } & \text { That's right, you can make a cost-benefit ((analysis)) of anything } \\ \text { Laura: } & \text { Wouldn't you be the man to do it along with me? }\end{array}$

Noticeable in this last excerpt is Laura's proposal that the action plan should read 'Get data', which leads Huey to argue that if they can only document relatively little downtime ('one and a half hours'), they are likely to get a negative reply from the management. However, Huey's example is reframed by Jimmy as actually being profitable, thereby revitalizing the operators' sensemaking on the issue.

Thus, while this workshop began with the operators presenting accounts of how they would not be able to solve the specific issue the sensemaking trajectory took a turn. Laura's account regarding the increased production demands marked a new situation and framed Huey's idea of available maintenance as a virtual necessity, ultimately changing the employees' enacted task-related control. In addition, the employees' realization that they might be able to sway senior management by adopting the economically based cost-benefit logics motivated the participants to agree on an action plan, highlighting a new path to higher tied job control.

\section{Sequence 3 - Expanding job control within organizational ties}

While the operators' job control was mostly discussed in sequences 1 and 2 in terms of whether an action plan should be pursued or not, their sensemaking also revolved around which of the available approaches towards an issue would be likely to allow the employees the most influence. Once again, the workshop studied in this third sequence started with some protests from the operators regarding the agenda, with the employees also criticizing senior management for having failed to resolve various (for them) 
well-known issues. Laura acknowledged the operators' stance by stating '... I don't disagree, but again it's simply outside my action radius', arguing that the company had to prioritize its investments.

After some discussion, the facilitator drew attention to the issues identified at the screening workshop. In relation to an especially strenuous task involving the extraction of sticky material from 'stupid canisters', the facilitator mentioned an offer from the intervention project group: The operators had the opportunity to bring in an external occupational therapist to evaluate their physical work environment. Tony, an operator, accepted the offer as a potentially useful intervention by suggesting that the occupational therapist could observe the strenuous task. However, he changed his mind when he learned that the therapist primarily gave advice on the operators' work posture, a solution he considered inadequate. Instead, Tony argued that they had to acquire completely new canisters. Another operator, Bob, began describing an idea for a new canister design he had been thinking about. Laura and the facilitator, on the other hand, continued arguing for the idea of contacting the occupational therapist:

Laura: $\quad$ I just want to say that what I experienced with ((the physical therapist; clause is incomplete)), she goes out to companies and looks at their work processes and helps change the work processes so they become less toilsome for the body

Tony: $\quad$ Oh yeah? Well she can't do that here

Laura: $\quad$ Yes, I think she can

Tony: $\quad$ No

Laura: I think she can, I, I have seen some other stuff she is doing, I think she can

While bringing in the occupational therapist was eventually agreed upon as an action plan, Bob was still adamant about developing new canisters. Laura argued that previous improvements developed by the operators themselves had eventually failed to ameliorate the targeted issues 'because we don't have enough knowledge about ergonomics or how the body works'. Laura then suggested that Bob could participate in the assessment conducted by the occupational therapist and suggested that Bob write down his design idea as a potential future action plan, which he did.

When Bob described his design proposal in more detail later in the workshop, the other participants responded mostly positive to his suggestion. However, another operator related that upper management had previously rejected a similar suggestion, and the discussion turned to how the participants could influence senior management to allow the development of new equipment. In line with the previous sequence, Laura encouraged the operators to calculate how much lost production time the solution could prevent. She did however also encourage the operators to invite the occupational therapist in to get expert knowledge in regards to the ergonomics of canister design. Tony, who was originally skeptical of contacting the occupational therapist, now tried to get Bob to join him in contacting the occupational therapist as a way to work towards a solution:

Tony: We have to get the occupational therapist in first, Bob

Laura: Just get the expert in first, then we can say 'we've got this problem', then she can come up with two proposals 
Tony: $\quad$ Yes, then we can take it to the management afterwards

Laura: $\quad$ Then afterwards you can take it to the management, 'we've gotten a new model that solves the red factors that we have in our workflow'

While Bob was reluctant, Tony and Laura eventually persuaded him into discussing his idea with the occupational therapist. Thus, the resulting action plan mainly reflected the facilitator's proposal, leaving Bob's suggestion as a potential later step.

The sequence thus illustrates how POLIs may create dilemmas about how to assess and enact one's job control based on the inherent unpredictability of whether one's attempts to influence the work environment will be successful. In the sequence, Laura used the action radius concept to remind the group not of the extent of their job control, but rather how their job control was tied to a certain approach (contacting the physical therapist). She also tapped into the same theme of establishing legitimacy towards senior management as we saw in Sequence 2. Sequence 3 however highlights a paradox: in order to make the most of their control, POLI participants may have to de-emphasize some of their suggestions in favor of those acceptable to management. Such choices are ultimately a product of the participants' collective sensemaking.

\section{Discussion}

As stated, the aim of this paper is to critically engage with the current main conceptualizations of the POLI-job control link and to present a supplementary conception highlighting the importance of collective sensemaking processes. In the analysis, we exemplified how POLI participants enact their job control in practice. Specifically, we showed how participants made sense of their situation and thereby gravitated towards certain courses of action while avoiding others. Through the presented sequences, we have shown that it is possible to follow trajectories of interaction and identify how job control in POLIs is negotiated on a turn-by-turn basis in collective sensemaking processes.

The three sequences present different examples of how participants' sensemaking can develop during POLI activities. In Sequence 1, the negotiations between the facilitator and the operators regarding the limits of their action radius can be seen as an example of how sensemaking processes in POLIs can activate employees' accounts of having too little general job control to change the work environment. Such accounts are important because they can lead to general resistance towards the POLI. In Sequence 2, the line manager's pressure for collecting data and proffering suggestions upwards through the management system challenged the operators' account of not being able to influence the organization. This sequence highlights how enactments of job control can be influenced if accounts emerge that provide participants with viable strategies for addressing relevant problems. In Sequence 3, we followed how a plan for changing problematic work processes made multiple shifts before its finalization. After extensive discussions, the participants reached an agreement in line with some of the participants' articulated preference, but against the proposing participant's original suggestion. The sequence illustrates how making decisions in participatory processes also involves compromises for the employees. Influencing the work environment is sometimes dependent on the participants' willingness to follow strategies they partly disapprove of.

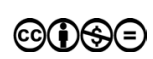


In relation to the conceptualization of job-control, our findings open for new nuances. When job control is enacted in participatory processes, it is subject to ongoing negotiations among the participants. The collective sensemaking perspective highlights that in POLIs, job control is sometimes enacted as stable and at other times dynamic, depending on the flow of the conversation. Conceptualizing job control as an aspect of working life that is negotiated and enacted by employees brings with it a new vantage point to the POLI literature. Most POLI research is based on measurements on individuals' perceptions of job control, while the link between job control and POLIs has been black-boxed, and researchers have predominantly assessed it as a product of individuals' cognitive processes. In comparison, a collective sensemaking approach focuses specifically on how social processes influence how employees express and enact their job control.

\section{Implications for POLI research}

As a result of the different ways in which participants enact their job control, participatory processes contain an element of unpredictability and improvisation: what is deemed impossible by the participants in one workshop may be seen as possible by the participants in another workshop. This leads to different sensemaking, different ways of engaging in the activities, and different outcomes. While it has been documented that employees manage their engagement in participatory activities to reflect the expected efficacy of their efforts (Harlos 2001; Pohler \& Luchak 2014), our analysis suggests that the employees' engagement is managed on an ongoing basis, and thus subject to changes, even in the short term. Thus, it is relevant for future POLI evaluation studies to focus more on specific POLI activities and how the success or failure of these may contribute to the overall effects observed.

Seeing job control as socially enacted and linked to collective sensemaking implies reconsidering previous explanations of how POLIs affect and build upon the participants' job control. Mikkelsen and colleagues (2000: 157) suggest that POLI participants engage in 'active learning' by identifying and solving problems, which increases their capacity to influence their working conditions and thus their job control. In a similar vein, Nielsen (2013) proposed that POLI participants are likely to engage in increased job crafting, whereby they modify their demanding work conditions to better suit their resources. However, based on our study, it seems plausible that these outcomes are not triggered simply by taking part in POLIs. Instead, such outcomes are more likely to surface when engagement in the POLIs has positively affected the participants' perceived capability for changing their own circumstances (Bandura 1986). As both our study and the data suggest, this is unfortunately often not the case.

\section{Implications for practice}

As it is becoming increasingly accepted that organizational interventions must fit the context to succeed (Nielsen \& Randall 2015), there is a growing demand to relate to more specific considerations and recommendations relevant for practitioners. Based on our study, we highlight three implications for POLI practice. 
First, employees enter POLIs with a set of experience-based expectations, which influence how they engage in the participatory process (Harlos 2001; Pohler \& Luchak 2014). Our analysis shows how experience can manifest as cues in the sensemaking process and become central for the employees' willingness to engage with the activities. While some accounts are more difficult to destabilize than others, the analysis shows that negative expectations can be reconstructed through credible and contextualized sensemaking, which suggests new and feasible strategies. We thus advise practitioners to assess the fit with the organizational context before initiating participatory processes. Here, the POLI history is relevant: are POLIs, and similar initiatives, frequent or rare? Do POLIs in general have a good or a bad reputation? To get as much benefit from the POLI activities as possible, POLIs need to be designed to manage the participants' expectations and facilitate the identification of new relevant strategies for action.

Second, the analysis shows how management and specific managers can influence POLI processes. For example, Laura came to influence the sensemaking processes substantially, in spite of instructions to remain predominantly passive. Laura's actions demonstrate how power asymmetries among POLI participants are not automatically cancelled out by the 'participatory' status of the activities. Rather, POLI processes are at risk of being hijacked by managers who push own agendas, potentially even against the interests of the employees. While managers have more decision authority and the right to expel undesired employees, observations of POLI-activities reveal that managers in these settings may avoid using strict coercive power to realize influence in decision making, instead investing substantial effort into constructing their viewpoints as being legitimate (Wåhlin-Jacobsen 2020; Wåhlin-Jacobsen \& Abildgaard 2020). Thereby, both employees and managers take part in the struggles for defining the organizational conditions under which decisions are made. As a consequence, the likelihood of employees' suggestions becoming implemented is not determined only by the immanent qualities of their ideas or the support within the group of colleagues, but also by the participants' negotiations of the understanding of the underlying problem, the possibilities for influence available, and the conditions that employees face in order to have their ideas accepted (Wåhlin-Jacobsen 2019). Thus, there are a number of potential pitfalls to POLI processes that may cause these to have only little or no effect, especially in conflictual settings.

Beyond the immediately present manager, our study also demonstrated that factors such as distance from the POLI to senior management became central to the sensemaking processes. In particular, addressing how to influence senior management turned out to be a prerequisite for the success of the workshop when employees' expectations were negative. Depending on the power distance in the organization, the POLI should be designed in a way that increases the chances of sensemaking processes that point towards feasibility of change. Taken together, balancing managers' and employees' interests in POLI sensemaking processes pose dilemmas to facilitators and demand much attention.

Third, viable strategies for influencing the work environment are linked to participants' engagement with the POLI. Though the employees across the three teams performed the same work tasks and had the same line managers, they varied greatly in terms of being able to locate viable strategies for influencing. Absence of new ideas or perspectives can strengthen existing accounts of insufficient job control and lead to further frustration. The importance of attentive facilitation, and thoughtful design of POLI activities that facilitates identification of new strategies, cannot be understated. 


\section{Conclusion}

In this article, we have argued that our understanding of the link between POLIs and job control can be advanced using a collective sensemaking lens. We demonstrated this through analysis of three sequences of workshop interaction. Seeing POLIs as arenas of sensemaking may help researchers see how POLI processes both influence, and are influenced by, job control. On this basis, we argue that POLIs should be studied as contextualized social activities wherein successfully increasing job control depends to a large extent on how employees make sense of their organizational environment.

Our study holds several potential limitations. First, we do not account for what happened after the POLI activities. The changes that participants decided to pursue may have been turned down elsewhere in the organization, which could have led them to perceive and enact their job control as diminished. A follow-up study that tracked the action plans after the POLI could have enriched the study. Second, the choice of a sensemaking analysis framework was based on initial coding stages, but other frameworks could have been employed which would have accentuated other aspects. For instance, a critical management approach (Alvesson \& Willmott 1992) would emphasize the power difference between managers and employees and a discourse analysis perspective could have focused on the discursive construction of different issues (Ritchie 2012). Third, we have not been able to show how changes in the participants' job control enactment is reflected in other types of data, such as questionnaire responses. However, as we have shown, employees enact different conceptualizations of job control at different times, with domain-specific and tied forms of job control being important in POLI processes, suggesting that current global job control measures might not be sensitive to the changes POLIs are likely to entail.

Despite the limitations, we argue that much insight can be gained by following this paper's example. Methodologically, studying social interaction, sensemaking and accounts allows us to see how job control is negotiated among POLI participants on a turn-by-turn basis, presenting an alternative to strict focus on the post-hoc questionnaire-based evaluation. A benefit of this approach is that it sheds light on how both formal and informal aspects of job control shape employees' accounts, and how job control can be enacted as both a stable aspect of the job and as a dynamic property of the situation. In addition, the study responds to the call for more qualitative research on participatory interventions (Egan et al. 2007). This paper does not mean to provide exhaustive account for the POLI-job control link. However, we hope to motivate other scholars to embark on unpacking the dynamics of participatory processes in workplaces, and examine other well-known concepts in the Nordic working life literature by studying them in detail.

\section{Acknowledgments}

This work was supported by the Danish Working Environment Research Fund, (grant 44-2014-03), drawing on data collected with funding from the Danish Government Rate Adjustment Pool (Satspulje, 2012; Nye Veje). 


\section{References}

Abildgaard J. S. and Nielsen K. (2018). The interplay of sensemaking and material artefacts during interventions: a case study, Nordic Journal of Working Life Studies 8(3). doi: https://doi.org/10.18291/njwls.v8i3.109538.

Abildgaard J. S., Hasson H., Schwarz U. von T., et al. (2018). Forms of participation: the development and application of a conceptual model of participation in work environment interventions, Economic and Industrial Democracy: 1-24. doi: https://doi.org/ 10.1177/0143831X17743576.

Ala-Laurinaho A., Kurki A-L and Abildgaard J. S. (2017). Supporting sensemaking to promote a systemic view of organizational change - contributions from activity theory, Journal of Change Management 17(4): 367-387. doi: https://doi.org/10.1080/1469701 7.2017.1309566.

Alvesson M. and Willmott H. (1992). On the idea of emancipation in management and organization studies, Academy of Management Review 17(3): 432-464. doi: http://dx.doi. org $/ 10.2307 / 258718$.

Aronsson G., Taloyan M., Westerlund H., et al. (2019). Associations between being 'lockedin' and health - an epidemiological study, Nordic Journal of Working Life Studies. doi: https://doi.org/10.18291/njwls.v9i3.116057.

Bakker A. B. and Demerouti E. (2007). The job demands-resources model: state of the art, Journal of Managerial Psychology 22(3): 309-328. doi: https://doi.org/10.1108/026839 40710733115.

Bambra C., Egan M., Thomas S., et al. (2007). The psychosocial and health effects of workplace reorganisation. 2. A systematic review of task restructuring interventions, Journal of Epidemiology and Community Health 61(12): 1028-1037. doi: https://doi.org/10.1136/ jech.2006.054999.

Bandura A. (1986). Social Foundations of Thought and Action: A Social-Cognitive View, Englewood Cliffs, NJ: Prentice Hall.

Boden D. (1994). The Business of Talk. Organizations in Action, Cambridge: Polity.

Bond F. W. and Bunce D. (2001). Job control mediates change in a work reorganization intervention for stress reduction, Journal of Occupational Health Psychology 6(4): 290. doi: https://doi.org/10.1037/1076-8998.6.4.290.

Bourbonnais R. (2006). Effectiveness of a participative intervention on psychosocial work factors to prevent mental health problems in a hospital setting, Occupational and Environmental Medicine 63(5): 335-342. doi: https://doi.org/10.1136/oem.2004. $\underline{018077 .}$.

Bourbonnais R., Brisson C. and Vézina M. (2011). Long-term effects of an intervention on psychosocial work factors among healthcare professionals in a hospital setting, Occupational and Environmental Medicine 68(7): 479-486. doi: https://doi.org/10.1136/oem. 2010.055202.

Boyce M. E. (1995). Collective centring and collective sense-making in the stories and storytelling of one organization, Organization Studies 16(1): 107-137. doi: https://doi. org/10.1177/017084069501600106.

Breaugh J. A. (1985). The measurement of work autonomy, Human Relations 38(6): 551-570. doi: https://doi.org/10.1177/001872678503800604.

Burton J. (2010). WHO Healthy Workplace Framework and Model: Background and Supporting Literature and Practice, Geneva, Switzerland: World Health Organization.

Busck O., Knudsen H. and Lind J. (2010). The transformation of employee participation: Consequences for the work environment, Economic and Industrial Democracy 31(3): 285-305. doi: https://doi.org/10.1177/0143831X09351212. 
Dahl-Jørgensen C. and Saksvik P. Ø. (2005). The impact of two organizational interventions on the health of service sector workers, International Journal of Health Services 35(3): 529-549. doi: https://doi.org/10.2190/P67F-3U5Y-3DDW-MGT1.

Daniels K. (2006). Rethinking job characteristics in work stress research, Human Relations 59(3): 267-290. doi: https://doi.org/10.1177/0018726706064171.

Egan M., Bambra C., Thomas S., et al. (2007). The psychosocial and health effects of workplace reorganisation. 1. A systematic review of organisational-level interventions that aim to increase employee control, Journal of Epidemiology and Community Health 61(11): 945-954. doi: https://doi.org/10.1136/jech.2006.054965.

European Network for Workplace Health Promotion (2007). Luxembourg Declaration on Workplace Health Promotion in the European Union, Brussels: ENWHP.

Fritz C. and Knippenberg D. (2019). Gender and Leadership Aspiration: Supervisor Gender, Support, and Job Control, Applied Psychology: apps.12197. doi: https://doi.org/10.1111/ apps.12197.

Gangster D. (1988). Improving measures of worker control in occupational stress research. In: Hurrell Jr. J. J., Murphy L. R., and Sauter S. L. (eds) Occupational Stress: Issues and Development in Research, Philadelphia, PA: Taylor \& Francis, pp. 88-99. doi: https://doi. org/10.1177/014920639101700202.

Garfinkel H. (1967). Studies in Ethnomethodology, Cambridge: Polity.

Gonzalez-Mulé E. and Cockburn B. (2017). Worked to death: the relationships of job demands and job control with mortality, Personnel Psychology 70(1): 73-112. doi: https://doi. org/10.1111/peps.12206.

Gupta N., Wåhlin-Jacobsen C. D., Henriksen L. N., et al. (2015). A participatory physical and psychosocial intervention for balancing the demands and resources among industrial workers (PIPPI): study protocol of a cluster-randomized controlled trial, BMC Public Health 15(1): 274. doi: https://doi.org/10.1186/s12889-015-1621-9.

Harlos K. P. (2001). When organizational voice systems fail. more on the deaf-ear syndrome and frustration effects, The Journal of Applied Behavioral Science 37(3): 324-342. doi: https://doi.org/10.1177/0021886301373005.

Hätinen M., Kinnunen U., Pekkonen M., et al. (2007). Comparing two burnout interventions: Perceived job control mediates decreases in burnout, International Journal of Stress Management 14(3): 227. doi: https://doi.org/10.1037/1072-5245.14.3.227.

Häusser J. A., Mojzisch A., Niesel M., et al. (2010). Ten years on: a review of recent research on the Job Demand-Control (-Support) model and psychological well-being, Work \& Stress 24(1): 1-35. doi: https://doi.org/10.1080/02678371003683747.

Karasek R. and Theorell T. (1990). Healthy Work: Stress, Productivity, and the Reconstruction of Working Life, New York: Basic Books.

Landsbergis P. A. and Vivona-Vaughan E. (1995). Evaluation of an occupational stress intervention in a public agency, Journal of Organizational Behavior 16(1): 29-48. doi: https:// doi.org/10.1002/job.4030160106.

Maes S., Verhoeven C., Kittel F., et al. (1998). Effects of a Dutch work-site wellness-health program: the Brabantia Project, American Journal of Public Health 88(7): 1037-1041.

Maitlis S. (2005). The social processes of organizational sensemaking, The Academy of Management Journal 48(1): 21-49. doi: https://doi.org/10.2307/20159639.

Mikkelsen A., Saksvik P. Ø. and Landsbergis P. (2000). The impact of a participatory organizational intervention on job stress in community health care institutions, Work \& Stress 14(2): 156-170. doi: https://doi.org/10.1080/026783700750051667.

Nielsen K. and Miraglia M. (2017). What works for whom in which circumstances? On the need to move beyond the 'what works?' question in organizational intervention research, Human Relations 70(1): 40-62. doi: https://doi.org/10.1177/0018726716670226. 
Nielsen K. and Randall R. (2015). Assessing and Addressing the Fit of Planned Interventions to the Organizational Context. In: Karanika-Murray M. and Biron C. (eds) Derailed Organizational Interventions for Stress and Well-Being, Dordrecht: Springer Netherlands, pp. 107-113. doi: https://doi.org/10.1007/978-94-017-9867-9 12.

Nielsen K. M. (2013). Review article: how can we make organizational interventions work? Employees and line managers as actively crafting interventions, Human Relations 66(8): 1029-1050. doi: https://doi.org/10.1177/0018726713477164.

Nielsen K. M., Randall R., Holten A-L, et al. (2010). Conducting organizational-level occupational health interventions: what works? Work \& Stress 24(3): 234-259. doi: https:// doi.org/10.1080/02678373.2010.515393.

Parker L. and Price R. (1994). Empowered managers and empowered workers: the effects of managerial support and managerial perceived control on worker's sense of control over decision making, Human Relations 47: 911-929. doi: https://doi.org/10.1177/ 001872679404700803.

Pennanen E. and Mikkola L. (2016). Work coordination as a social interaction process in nursing staff meetings, Nordic Journal of Working Life Studies 6(2): 23. doi: https://doi. org/10.19154/njwls.v6i2.4970.

Pohler D. M. and Luchak A. A. (2014). The missing employee in employee voice research. In: Wilkinson A., Donaghey J., Dundon T., et al. (eds) Handbook of Research on Employee Voice, Northampton, MA: Edward Elgar Publishing. doi: https://doi.org/10.4337/97808 57939272.00020.

Ritchie L. (2012). Negotiating power through communication: using an employee participation intervention to construct a discursive space for debate, Journal of Communication Management 16(1): 95-107. doi: https://doi.org/10.1108/13632541211198003.

Saldaña J. (2015). The Coding Manual for Qualitative Researchers. 3rd ed., Los Angeles, Calif. London: SAGE Publications Ltd.

Taylor J. R. and Robichaud D. (2004). Finding the organization in the communication: Discourse as action and sensemaking, Organization 11(3): 395-413. doi: https://doi. org/10.1177/1350508404041999.

The National Research Centre for the Working Environment (2018). Work environment and health 2018 (Arbejdsmiljø og Helbred 2018). Available at: https://arbejdsmiljodata.nfa.dk/.

Tsutsumi A., Nagami M., Yoshikawa T., et al. (2009). Participatory intervention for workplace improvements on mental health and job performance among blue-collar workers: a cluster randomized controlled trial, Journal of Occupational and Environmental Medicine 51(5): 554-563. doi: https://doi.org/10.1097/JOM.0b013e3181a24d28.

Väänänen A. and Toivanen M. (2018). The challenge of tied autonomy for traditional work stress models, Work \& Stress 32(1): 1-5. doi: https://doi.org/10.1080/02678373.2017.1 415999.

Van der Doef M. and Maes S. (1999). The job demand-control (-support) model and psychological well-being: a review of 20 years of empirical research, Work \& Stress 13(2): 87-114. doi: https://doi.org/10.1080/026783799296084.

Van Maanen J. (2011). Tales of the Field: On Writing Ethnography, Chicago: University of Chicago Press.

Wåhlin-Jacobsen C. D. (2019). The terms of 'becoming empowered': How ascriptions and negotiations of employee identities shape the outcomes of workplace voice activities, Scandinavian Journal of Management 35(3): 101059. doi: https://doi.org/10.1016/j.scaman. 2019.101059.

Wåhlin-Jacobsen C. D. (2020). Open or closed? A social interaction perspective on line managers' reactions to employee voice, Management Communication Quarterly 34(1): 32-57. doi: https://doi.org/10.1177/0893318919879901. 
Wåhlin-Jacobsen C. D. and Abildgaard J. S. (2020). Only the wearer knows where the shoe pinches? Deontics and epistemics in discussions of health and well-being in participatory workplace settings, Discourse \& Communication 14(1): 44-64. doi: https://doi. org $/ 10.1177 / 1750481319876768$.

Wåhlin-Jacobsen C. D., Henriksen L. N., Abildgaard J. S., et al. (2017). Styrk Arbejdsmiljøet Med Medarbejderne - En Metode Til at Skabe Forbedringer i Arbejdsmiljøet Ved at Inddrage de Ansatte, København: Det Nationale Forskningscenter for Arbejdsmiljø. Available at: http://www.arbejdsmiljoforskning.dk/ /media/Boeger-og-rapporter/SAMmanual/SAM-manual.pdf.

Wall T. D. and Clegg C. (1981). A longitudinal field study of group work redesign. Journal of Organizational Behavior 2(1): 31-49. doi: https://doi.org/10.1002/job.4030020104.

Weick K. E. (1977). Enactment processes in organizations. In: Salancik G. R. and Staw B. M. (eds) New Directions in Organizational Behavior, Chicago: St. Clair, pp. 267-300.

\section{Note}

${ }^{1}$ For the remainder of the paper, the term 'operator' is used when discussing the specific employees who are represented in our data, while 'employee' is used to refer to employees in POLIs in general. 